\section{JURNAL EKONOMI EFEKTIF}

ISSN : $2622-8882$, E-ISSN : 2622-9935

Jurnal Ekonomi Efektif, Vol. 2, No. 3, April 2020

@Prodi Manajemen Fakultas Ekonomi Universitas

Pamulang

\title{
PENGARUH KUALITAS PELAYANAN, KUALITAS PRODUK DAN NILAI NASABAH TERHADAP KEPUASAN NASABAH PADA PT. BPR SYARIAH X
}

\author{
Ivantan $^{1^{*}}$, Aris Ariyanto ${ }^{2}$ Purwanti $^{3}$ \\ Universitas Pamulang \\ dosen02504@unpam.ac.id*
}

\begin{abstract}
ABSTRAK
Tujuan penelitian adalah untuk mengetahui Fenomena serta kesimpulan mengenai pengaruh ke tiga variabel bebas terhadap kepuasan nasabah pada PT. BPR Syariah X. Penelitian ini bersifat Asosiatif dengan pendekatan kuantitatif. Sampel yang digunakan dalam penelitian ini sebanyak 98 responden. Teknik analisis data yang digunakan dalam penelitian ini dengan menggunakan analisis statistik dengan pengujian regresi, korelasi, determinasi dan uji hipotesis. Hasilpenelitian secara simultan didapatkan kualitas pelayanan, kualitas produk dan nilai nasabah berpengaruh positif dan signifikan terhadap kepuasan nasabah pada PT. BPR Syariah X. Hal ini dapat dilihat dari persamaan regresi linier berganda yaitu $\mathrm{Y}=6,530+0.167 \mathrm{X}_{1}+0.315 \mathrm{X}_{2}+0.365 \mathrm{X}_{3}$, nilai koefisien korelasi yang ditemukan sebesar 0,619 , koefisien determinasi sebesar 38,4\% dan nilai Fhitung 19,508>F tabel 2,70 dengan siginifiakan $0,000<0,05$
\end{abstract}

Kata Kunci: Kualitas Pelayanan, Kualitas Produk, Nilai Nasabah, Kepuasan Nasabah.

\begin{abstract}
The research objective was to determine the phenomenon and conclusions regarding the effect of the three independent variables on customer satisfaction at PT. BPR Syariah X. This research is associative with a quantitative approach. The sample used in this study were 98 respondents. Data analysis techniques used in this study using statistical analysis with regression testing, correlation, determination and hypothesis testing. The results of the research simultaneously show that service quality, product quality and customer value have a positive and significant effect on customer satisfaction at PT. BPR Syariah X. This can be seen from the multiple linear regression equation, namely $Y=6,530+0.167 X 1+0.315 X 2+$ $0.365 X 3$, the value of the correlation coefficient found is 0.619 , the coefficient of determination is $38.4 \%$ and the Fcount value is 19.508> F table 2, 70 with a siginifiable $0.000<0.05$
\end{abstract}

Keywords: Service Quality, Product Quality, Customer Value, Customer Satisfaction. 


\section{PENDAHULUAN}

\section{A. Latar Belakang Masalah}

Kualitas layanan merupakan salah satu perhatian utama nasabah dalam memilih Bank. Menurut Tjiptono (2012:75) layanan atau jasa merupakan "suatu perbuatan, tindakan, pengalaman, proses, kinerja (performance) atau usaha yang sifatnya abstrak". Jadi kualitas bank yang baik adalah apabila bank tersebut dapat memahami dan mengerti kebutuhan-kebutuhan dari nasabahnya.

Kualitas produk saat ini sangat diperhatikan oleh konsumen. Konsumen menginginkan kualitas produk yang terbaik pada produk-produk yang telah dibeli. Menurut Kotler (2012:78) kualitas produk adalah ciri dan karakteristik suatu barang atau jasa yang berpengaruh pada kemampuannya untuk memuaskan kebutuhan yang dinyatakan atau tersirat. Untuk mencapai kualitas produk yang diinginkan maka diperlukan suatu standarisasi kualitas. Cara ini dimaksudkan untuk menjaga agar produk yang dihasilkan memenuhi standar yang telah ditetapkan sehingga konsumen tidak akan kehilangan kepercayaan terhadap produk yang bersangkutan.

Kepuasan konsumen merupakan faktor yang sangat penting bagi keberadaan, kelangsungan, dan perkembangan perusahaan. Saat ini banyak perusahaan yang semakin memahami arti penting dari kepuasan konsumen dan menjalankan strategi guna memberikan kepuasan bagi konsumennya. Menurut Tjiptono (2012:146) kepuasan konsumen merupakan evaluasi purnabeli dimana sekurang-kurangnya memberikan hasil (outcome) sama atau melampaui harapan pelanggan. Sedangkan ketidakpuasan timbul apabila hasil yang diperoleh tidak memenuhi harapan pelanggan.

Bank Pembiayaan Rakyat Syariah X merupakan salah satu BPR Syariah yang tumbuh di Indonesia khususnya di wilayah Bogor, dengan tujuan utamanya adalah untuk memberdayakan usaha kecil atau mikro yang selama ini kesulitan mendapatkan pelayanan perbankan.

Masalah yang dihadapi PT. BPR Syariah X sekarang ini adalah jumlah nasabah yang menutup rekening tabungan mengalami peningkatan setiap tahunnya. Hal tersebut dapat menjadi gambaran bahwa ada masalah kepuasan nasabah pada PT. BPR Syariah X.

Permasalahan yang terjadi pada kualitas produk BPR Syariah X adalah tidak adanya kartu ATM bagi para nasabahnya, ATM adalah salah satu bentuk produk perbankan hasil teknologi (komputer) dalam upaya peningkatan pelayanan bank kepada nasabah.

Permasalahan yang terjadi atas menurunnya jumlah nasabah yang membuka tabungan adanya kemungkinan perusahaan belum mampu memberikan layanan terbaik atau memberikan kepuasan terbaiknya kepada nasabahnya, karena nasabah merasa belum mendapatkan nilai lebih selama menabung sehingga nasabah tidak merekomendasikan kepada orang lain. Melihat fenomena ini, maka perusahaan harus meningkatkan kualitas pelayanan dan kualitas produk agar keadaan seperti ini tidak berulang atau bertambah di masa mendatang.

Adapun permasalahan lain yang dikeluhkan nasabah pada PT. BPR Syariah X, adalah seperti: Kurangnya fasilitas yang disediakan pihak-pihak PT. BPR Syariah X sehingga pada saat nasabah ingin membuka rekening ataupun adanya keluhan lainnya, nasabah harus berdiri, karena kurangnya fasilitas yang disediakan, sehingga menyebabkan ketidakpuasan pelanggan.

Nilai bagi nasabah bisa juga dilihat sebagai cerminan dari kualitas, manfaat dan pengorbanan yang diberikan untuk mendapatkan sebuah produk atau layanan. Sebuah produk atau layanan perbankan dikatakan mempunyai nilai yang tinggi di mata nasabah apabila mampu memberikan kualitas, manfaat dan pengorbanan yang seminimal mungkin. Jika Bank syariah dapat memberikan manfaat yang sesuai bahkan lebih dari 
biaya yang dikeluarkan nasabah, maka akan memberikan kepuasan tersendiri bagi nasabah.

Berdasarkan uraian di atas, maka penulis tertarik melakukan penelitian dengan judul: "Pengaruh Kualitas Pelayanan, Kualitas Produk dan Nilai Nasabah Pada Kepuasan Nasabah PT. BPR Syariah X".

\section{B. Perumusan Permasalahan Penelitian}

1. Apakah kualitas pelayanan berpengaruh positif dan signifikan terhadap kepuasan nasabah pada PT. BPR Syariah X?

2. Apakah kualitas produk berpengaruh positif dan signifikan terhadap kepuasan nasabah pada PT. BPR Syariah X?

3. Apakah nilai nasabah berpengaruh positif dan signifikan terhadap kepuasan nasabah pada PT. BPR Syariah X?

4. Apakah kualitas pelayanan, kualitas produk, dan nilai nasabah berpengaruh positif dan signifikan secara simultan terhadap kepuasan nasabah pada PT. BPR Syariah X?

\section{Manfaat Penelitian}

1. Untuk mengetahui dan menganalisis pengaruh kualitas pelayanan terhadap kepuasan nasabah pada PT. BPR Syariah X

2. Untuk mengetahui dan menganalisis pengaruh kualitas produk terhadap kepuasan nasabah pada PT. BPR Syariah X

3. Untuk mengetahui dan menganalisis pengaruh nilai nasabah terhadap kepuasan nasabah pada PT. BPR Syariah X

4. Untuk mengetahui dan menganalisis pengaruh kualitas pelayanan, kualitas produk, dan nilai nasabah secara simultan terhadap kepuasan nasabah pada PT. BPR Syariah $\mathrm{X}$

\section{METODE PENELITIAN}

Populasi dalam penelitian ini berjumlah 5.059 responden PT. BPR Syariah X. Teknik pengambilan sampling dalam penelitian ini adalah proposional random sampling yakni pemilihan sampel dilakukan secara acak sederhana secara proporsional dengan cara diundi/dihitung proporsionalnya. Penentuan jumlah minimal sampel dapat dihitung dengan rumus Slovin. Dengan demikian sampel dalam penelitian ini berjumlah 98 responden. Jenis penelitian yang dipakai adalah asosiatif, dimana tujuannya adalah untuk mengetahui pengaruh antara variabel bebas terhadap variabel terikat baik parsial maupun simultan. Dalam menganalisis data digunakan uji instrumen, uji asumsi klasik, regresi, koefisien determinasi dan uji hipotesis.

\section{HASIL PENELITIAN DAN PEMBAHASAN}

\section{A. Hasil Penelitian}

\section{Analisis Regresi Linier Berganda}

Pada analisis ini dimaksudkan untuk mengetahui pengaruh variabel independen terhadap variabel dependen. Adapun hasil pengujian sebagai berikut:

Tabel 1. Hasil Pengujian Regresi Linier Berganda

\begin{tabular}{|c|c|c|c|c|c|}
\hline \multirow[b]{3}{*}{ Model } & \multirow{2}{*}{\multicolumn{2}{|c|}{$\begin{array}{l}\text { Coefficients }^{\mathbf{a}} \\
\text { Unstandardized } \\
\text { Coefficients }\end{array}$}} & \multirow{3}{*}{$\begin{array}{c}\text { Standardized } \\
\text { Coefficients } \\
\text { Beta }\end{array}$} & \multirow[b]{3}{*}{$t$} & \multirow[b]{3}{*}{ Sig. } \\
\hline & & & & & \\
\hline & $\mathrm{B}$ & Std. Error & & & \\
\hline $\begin{array}{ll}1 & \text { (Constant) }\end{array}$ & 6,530 & 4,821 & & 1,354 & 179 \\
\hline Kualitas Pelayanan (X1) & , 167 & 081 & , 181 & 2,063 & ,042 \\
\hline
\end{tabular}




\begin{tabular}{cc|c|r|r|r}
\hline Kualitas Produk (X2) &, 315 &, 107 &, 251 & 2,941 &, 004 \\
\hline Nilai Nasabah (X3) &, 365 &, 084 &, 395 & 4,364 &, 000 \\
\hline a. Dependent Variable: Kepuasan Nasabah (Y) & &
\end{tabular}

Berdasarkan hasil pengujian pada tabel di atas, diperoleh persamaan regresi $\mathrm{Y}=6,530+0.167 \mathrm{X}_{1}+0.315 \mathrm{X}_{2}+0.365 \mathrm{X}_{3}$.

\section{Analisis Koefisien Korelasi}

Analisis koefisien korelasi dimaksudkan untuk mengetahui tingkat kekuatan hubungan dari variabel independen terhadap variabel dependen secara simultan.

Tabel 2. Hasil Pengujian Koefisien Korelasi Kualitas Pelayanan, Kualitas Produk dan Nilai Nasabah secara simultan Terhadap Kepuasan Nasabah. Model Summary

\begin{tabular}{|c|c|c|c|c|}
\hline Model & $\mathrm{R}$ & R Square & $\begin{array}{l}\text { Adjusted R } \\
\text { Square }\end{array}$ & $\begin{array}{c}\text { Std. Error of the } \\
\text { Estimate }\end{array}$ \\
\hline 1 & ,619a & ,384 & ,364 & 3,765 \\
\hline
\end{tabular}
$(\mathrm{X} 1)$

Berdasarkan hasil pengujian diperoleh nilai korelasi sebesar 0,619

\section{Analisis Koefisien Determinasi}

artinya Kualitas Pelayanan, Kualitas Produk dan Nilai Nasabah secara simultan memiliki hubungan yang kuat terhadap Kepuasan Nasabah.

Analisis koefisien determinasi dimaksudkan untuk mengetahui besarnya persentase pengaruh dari variabel independen terhadap variabel dependen secara simultan.

Tabel 3. Hasil Pengujian Koefisien Determinasi Kualitas Pelayanan, Kualitas Produk dan Nilai Nasabah Terhadap Kepuasan Nasabah.

\begin{tabular}{|c|c|c|c|c|}
\hline \multicolumn{5}{|c|}{ Model Summary } \\
\hline Model & $\mathrm{R}$ & R Square & $\begin{array}{l}\text { Adjusted R } \\
\text { Square }\end{array}$ & $\begin{array}{l}\text { Std. Error of the } \\
\text { Estimate }\end{array}$ \\
\hline$\overline{1}$ & $619^{a}$ & ,384 & ,364 & 3,765 \\
\hline
\end{tabular}

Berdasarkan hasil pengujian diperoleh nilai determinasi sebesar 0,619 artinya Kualitas Pelayanan, Kualitas Produk dan Nilai Nasabah secara simultan memiliki kontribusi pengaruh sebesar $61,9 \%$ terhadap Kepuasan Nasabah, sedangkan sisanya sebesar 38,1\% dipengaruhi faktor lain

\section{Uji Hipotesis}

Pengujian hipotesis dengan uji $\mathrm{F}$ digunakan untuk mengetahui hipotesis simultan yang mana yang diterima. Hipotesis keempat Terdapat pengaruh yang signifikan antara Kualitas Pelayanan, Kualitas Produk dan Nilai Nasabah terhadap Kepuasan Nasabah.

Tabel 4. Hasil Uji Hipotesis Kualitas Pelayanan, Kualitas Produk dan Nilai Nasabah terhadap Kepuasan Nasabah.

\section{ANOVA $^{\mathrm{a}}$}

\begin{tabular}{ll|r|r|r|r|r} 
Model & & Sum of Squares & df & Mean Square & F & \multicolumn{1}{c}{ Sig. } \\
\hline 1 & Regression & 829,434 & 3 & 276,478 & 19,508 &, $000^{\mathrm{b}}$ \\
\cline { 2 - 7 } & Residual & 1332,240 & 94 & 14,173 & & \\
\cline { 2 - 7 } & Total & 2161,673 & 97 & & & \\
\hline
\end{tabular}


Berdasarkan hasil pengujian pada tabel di atas, diperoleh nilai $\mathrm{F}$ hitung > F tabel atau (19,508 > 3,09), dengan demikian hipotesis keempat yang diajukan bahwa terdapat pengaruh yang signifikan atara Kualitas Pelayanan, Kualitas Produk dan Nilai Nasabah terhadap Kepuasan Nasabah diterima.

\section{B. Pembahasan}

\section{Pengaruh Kualitas Pelayanan Terhadap Kepuasan Nasabah}

Berdasarkan hasil analisis regresi linier sederhana diperoleh persamaan $\mathrm{Y}=25,932+0,350 \mathrm{X}$ Artiya nilai (a) atau konstanta sebesar 25,932 nilai ini menunjukan bahwa pada saat kualitas pelayanan $\left(\mathrm{X}_{1}\right)$ bernilai nol atau tidak meningkat, maka kepuasan nasabah (Y) akan bernilai 25,932. koefisien regresi nilai (b) sebesar 0,350 (positif) yaitu menunjukkan pengaruh yang searah yang artinya setiap kenaikan kualitas pelayanan sebesar satu satuan maka akan meningkatkan kepuasan nasabah sebesar 0,350 satuan.

Nilai korelasi kualitas pelayanan $\left(\mathrm{X}_{1}\right)$ sebesar 0,381 menunjukan bahwa hubungan antara kualitas pelayanan $\left(\mathrm{X}_{1}\right)$ terhadap kepuasan nasabah $(\mathrm{Y})$ memiliki hubungan yang rendah.

Nilai koefisien determinasi sebesar 0,145 yang artinya bahwa kualitas pelayanan $\left(\mathrm{X}_{1}\right)$ memberikan kontribusi terhadap variabel kepuasan nasabah $(\mathrm{Y})$ sebesar $14,5 \%$, sedangkan sisanya sebesar $85,5 \%$ di pengaruhi oleh variabel lain yang tidak diteliti dalam penelitian ini.

Nilai t hitung kualitas pelayanan sebesar 4,041 > t tabel 1,984 dengan signifikan $0,000<0,05$ maka H0 ditolak dan Ha diterima menandakan bahwa kualitas pelayanan $\left(\mathrm{X}_{1}\right)$ mempunyai pengaruh yang positif dan signifikan terhadap kepuasan nasabah (Y).

\section{Pengaruh Kualitas Produk Terhadap Kepuasan Nasabah}

Berdasarkan hasil analisis regresi linier sederhana diperoleh persamaan $Y=20,058+0,509 X$, Artiya nilai (a) atau konstanta sebesar 20,058 nilai ini menunjukan bahwa pada saat kualitas produk $\left(\mathrm{X}_{2}\right)$ bernilai nol atau tidak meningkat, maka kepuasan nasabah (Y) akan bernilai 20,058. Koefisien regresi nilai (b) sebesar 0,509 (positif) yaitu menunjukkan pengaruh yang searah yang artinya setiap kenaikan kualitas produk sebesar satu satuan maka akan meningkatkan kepuasan nasabah sebesar0,509 satuan.

Nilai korelasi kualitas produk $\left(\mathrm{X}_{2}\right)$ sebesar 0,405 menunjukan bahwa hubungan antara kualitas produk $\left(\mathrm{X}_{2}\right)$ terhadap kepuasan nasabah $(\mathrm{Y})$ memiliki hubungan yang sedang.

Nilai koefisien determinasi sebesar 0,164 yang artinya bahwa kualitas produk $\left(\mathrm{X}_{2}\right)$ memberikan kontribusi terhadap variabel kepuasan nasabah $(\mathrm{Y})$ sebesar 16,4\%, sedangkan sisanya sebesar $83,6 \%$ di pengaruhi oleh variabel lain yang tidak diteliti dalam penelitian ini.

Nilai t hitung kualitas produk sebesar 4,340 > t tabel 1,984 dengan signifikan $0,000<0,05$ maka $\mathrm{H} 0$ ditolak dan Ha diterima menandakan bahwa kualitas produk $\left(\mathrm{X}_{2}\right)$ mempunyai pengaruh yang positif dan signifikan terhadap kepuasan nasabah (Y).

\section{Pengaruh Nilai Nasabah Terhadap Kepuasan Nasabah}

Berdasarkan hasil analisis regresi linier sederhana diperoleh persamaan $Y=20,747+0,498 X$, Artiya nilai (a) atau konstanta sebesar 20,747 nilai ini menunjukan bahwa pada saat nilai nasabah $\left(\mathrm{X}_{3}\right)$ bernilai nol atau tidak meningkat, maka kepuasan nasabah (Y) akan bernilai 20,747. Koefisien regresi nilai (b) sebesar 0,498 (positif) yaitu menunjukkan pengaruh yang searah yang artinya setiap kenaikan 
nilai nasabah sebesar satu satuan maka akan meningkatkan kepuasan nasabah sebesar 0,498 satuan.

Nilai korelasi nilai nasabah $\left(\mathrm{X}_{3}\right)$ sebesar 0,539 menunjukan bahwa hubungan antara nilai nasabah $\left(\mathrm{X}_{3}\right)$ terhadap kepuasan nasabah $(\mathrm{Y})$ memiliki hubungan yang sedang.

Nilai koefisien determinasi sebesar 0,291 yang artinya bahwa nilai nasabah $\left(\mathrm{X}_{3}\right)$ memberikan kontribusi terhadap variabel kepuasan nasabah (Y) sebesar 29,1\%, sedangkan sisanya sebesar $71,9 \%$ di pengaruhi oleh variabel lain yang tidak diteliti dalam penelitian ini.

Hasil uji t hitung nilai nasabah sebesar 6,277 > t tabel 1,984 dengan signifikan 0,000 $<0,05$ maka H0 ditolak dan Ha diterima menandakan bahwa nilai nasabah $\left(\mathrm{X}_{3}\right)$ mempunyai pengaruh yang positif dan signifikan terhadap kepuasan nasabah (Y).

\section{Pengaruh Kualitas Pelayanan, Kualitas Produk dan Nilai Nasabah Secara Simultan Terhadap Kepuasan Nasabah}

Berdasarkan hasil regresi linier berganda persamaan regresi yang diperoleh $\mathrm{Y}=6,530+0.167 \mathrm{X}_{1}+0.315 \mathrm{X}_{2}+0.365 \mathrm{X}_{3}$, Konstanta sebesar 6,530 menyatakan bahwa tanpa adanya kualitas pelayanan, kualitas produk dan nilai nasabah, kepuasan nasabah tetap terbentuk sebesar 6,530.

Nilai korelasi kualitas pelayanan $\left(\mathrm{X}_{1}\right)$, kualitas produk $\left(\mathrm{X}_{2}\right)$ dan nilai nasabah $\left(\mathrm{X}_{3}\right)$ sebesar 0,619 yang berarti bahwa hubungan antara kualitas pelayanan, kualitas produk dan nilai nasabah secara simultan terhadap kepuasan nasabah memiliki hubungan yang kuat.

Nilai koefisien determinasi sebesar 0,384 yang artinya bahwa kualitas pelayanan $\left(\mathrm{X}_{1}\right)$ kualitas produk $\left(\mathrm{X}_{2}\right)$ dan nilai nasabah $\left(\mathrm{X}_{3}\right)$ memberikan kontribusi terhadap variabel kepuasan nasabah (Y) sebesar 38,4\%, sedangkan sisanya sebesar $61,6 \%$ di pengaruhi oleh variabel lain yang tidak diteliti dalam penelitian ini.

Nilai $F$ hitung 19,508 $>\mathrm{F}$ tabel 3,09 dengan siginifiakan 0,000 $<0,05$ dengan demikian Ho ditolak dan Ha diterima, artinya secara simultan atau bersama-sama kualitas pelayanan, kualitas produk dan nilai nasabah berpengaruh positif dan signifikan terhadap kepuasan nasabah pada PT. BPR Syariah X.

\section{PENUTUP}

\section{A. Kesimpulan}

1. Kualitas Pelayanan berpengaruh signifikan terhadap Kepuasan Nasabah dengan kontribusi pengaruh sebesar $14,5 \%$. Uji hipotesis diperoleh nilai t hitung $>\mathrm{t}$ tabel atau $(4,041>1,984)$.

2. Kualitas Produk berpengaruh signifikan terhadap Kepuasan Nasabah dengan kontribusi pengaruh sebesar $16,4 \%$. Uji hipotesis diperoleh nilai t hitung $>\mathrm{t}$ tabel atau $(4,340>1,984)$.

3. Nilai Nasabah berpengaruh signifikan terhadap Kepuasan Nasabah dengan kontribusi pengaruh sebesar $29,1 \%$. Uji hipotesis diperoleh nilai $t$ hitung $>t$ tabel atau $(6,277>1,984)$.

4. Kualitas Pelayanan, Kualitas Produk dan Nilai Nasabah berpengaruh signifikan terhadap Kepuasan Nasabah dengan kontribusi pengaruh sebesar 38,4\% sedangkan sisanya sebesar $61,6 \%$ dipengaruhi faktor lain. Uji hipotesis diperoleh nilai $\mathrm{F}$ hitung $>\mathrm{F}$ tabel atau $(19,508>3,09)$. 


\section{B. Saran}

Berdasarkan hasil penelitian yang didapatkan maka saran yang ingin penulis sampaikan khususnya pada PT. BPR Syariah X yaitu:

1. PT. BPR Syariah $X$ dapat terus menjaga dan mengembangkan kualitas pelayanan kepada nasabah khususnya dari segi keramahan, kesantunan, kecepatan dan ketepatan dalam pemberian solusi dan penyelesaian masalah serta diharapkan untuk lebih memberikan perhatian khusus bagi nasabah yang memang belum pernah diberikan.

2. Untuk dapat meningkatkan kualitas produk pada PT. BPR Syariah X sebaiknya perusahaan meningkatkan dan mengembangkan produk yang dimiliki, contohnya dengan melakukan berbagai kreativitas dan inovasi terbaru dengan membuat kartu ATM bagi para nasabahnya guna meningkatkan kepuasan nasabah.

3. Nilai nasabah akan tercipta bila nasabah puas apabila mendapatkan manfaat dari biaya yang dikeluarkan untuk itu, perusahaan perlu meningkatkan interaksi pelanggan dengan service personnel, memperbaiki dan menambah kelengkapan fasilitas jasa serta kualitas pelayanan dan kenyamanan.

4. Untuk meningkatkan kepuasan nasabah penulis menyarankan agar kedekatan dengan nasabah perlu ditingkatkan lagi, dalam kaitannya keramahan karyawan, sikap karyawan saat nasabah datang, mengawali pelayanan, selama melayani, hingga mengakhiri pelayanan. Hal ini diharapkan agar terjadi hubungan timbal balik dengan nasabah supaya nasabah tidak ragu-ragu untuk mengemukakan keluhannya.

Untuk penelitian yang akan datang disarankan untuk menambah variabel independen lainnya selain kualitas pelayanan, kualitas produk dan nilai nasabah, yang tentunya dapat mempengaruhi variabel dependen kepuasan nasabah agar lebih melengkapi penelitian ini karena masih ada variabel-variabel independen lain di luar penelitian ini yang mungkin bisa mempengaruhi kepuasan nasabah seperti kedekatan emosional, kepercayaan, dan promosi.

\section{DAFTAR PUSTAKA}

Dahlan Siamat, 2001, Manajemen Lembaga Keuangan, Edisi Ketiga, Fakultas Ekonomi Indonesia, Jakarta.

Dharmmesta dan Handoko, 2011, Manajemen Pemasaran: Analisis Perilaku Konsumen, BPFE, Yogyakarta.

Djaslim Saladin, 2011, Manajemen Strategi dan Kebijakan Perusahaan, Edisi Lima, Linda Karya, Bandung.

Fatrio, 2006, Analisis faktor-faktor Yang Mempengaruhi Kepuasan Nasabah Dalam Meningkatkan Loyalitas Nasabah Studi Kasus: Pada PT. Bank Bukopin Kantor Cabang Tegal, Tesis, UNDIP, Semarang.

Gantara, Kumadji, dan Yulianto, 2013, Analisis Pengaruh Kualitas Layanan dan Perceived Value Terhadap Kepuasan Pelanggan dan Loyalitas Pelanggan Studi Empiris pada Mahasiswa Universitas Brawijaya Malang Pengguna Kartu Seluler IM3, Jurnal Universitas Brawijaya Malang.

George Terry, 2007, Principles of Management, PT. Bumi Aksara, Jakarta.

Ghozali, 2012, Aplikasi Analisis Multivariate Dengan Program SPSS. Badan Penerbit Undip. Semarang.

Gumilar, I., Sunarsi, D. (2020). Comparison of financial performance in banking with high car and low car (Study of banks approved in the kompas 100 index for the period 
2013-2017). International Journal of Psychosocial Rehabilitation. Volume 24 - Issue 7

Gusti Ayu Putu Ratih Kusuma Dewi, 2014, Pengaruh Kualitas Pelayanan Terhadap Kepuasan Dan Loyalitas Nasabah PT BPR Hoki Di Kabupaten Tabanan, Tesis Universitas Udayana Denpasar, Bali.

Handoko, 2012, Manajemen Personalia dan Sumber Daya Manusia, Penerbit, BPFE, Yogyakarta.

Hasibuan, 2014, Manajemen Sumber Daya Manusia, Edisi Revisi, PT Bumi Aksara, Jakarta.

Hendra dan Ronny A Rusly, 2012, Manajemen Pemasaran, edisi millenium, Penerbit PT. Indeks, Jakarta.

Hidayat, 2006, Pengaruh Kualitas Layanan, Kualitas Produk, Dan Nilai Nasabah Terhadap Kepuasan Dan Loyalitas Nasabah Tabungan Bank Mandiri di Jawa Timur. Desertasi. Program Studi Ilmu Ekonomi. Pascasarjana Universitas Airlangga.

Inka Janita Sembiring; Suharyono; Andriani Kusumawati, 2014, Pengaruh Kualitas Produk dan Kualitas Pelayanan Terhadap Kepuasan Pelanggan Dalam Membentuk Loyalitas Pelanggan Studi pada Pelanggan McDonald's MT.Haryono Malang, Jurnal Administrasi Bisnis (JAB) Vol. 15 No. 1 Oktober.

Irmal, I., Gustiarani, E., \& Sunarsi, D. (2020). Pengaruh E-Marketing dan E-CRM terhadap E-Loyalty Pengunjung Situs Website www. Cangkirbogor. com. Jurnal Ekonomi Efektif, 2(2).

Kotler dan Amstrong, 2013, Prinsip-Prinsip Pemasaran Jilid I. Erlangga, Jakarta.

Sunarsi, D., \& Baharuddin, A. (2019). The Effect of Service Quality and Price Accuracy on Consumer Confidence and Implications for Sales Increase. PINISI Discretion Review, 3(2), 101-110. 